\title{
Gender Identity in a Group of Retarded Children
}

\author{
Geoffrey Abelson ${ }^{1}$ \\ Iowa State University \\ Maria Paluszny \\ University of Michigan Medical Center
}

The Michigan Gender Identity Test (MGIT) was administered to 52 retarded and 36 normal children to assess the acquisition of gender identity. This instrument required the ability to sort and categorize photographs of boys and girls wearing conventional clothing and with conventional hairstyles. As part of the test, each child was expected to recognize a self-photo and to be able to categorize it as a boy or a girl. In general, a significant correlation was found between MGIT performance and mental age for the retarded children. The performance of the normal children correlated significantly with both chronological age and mental age.

\section{INTRODUCTION}

Psychosexual development of children has been studied from a variety of perspectives. Researchers have stressed the biological effects (Stoller, 1968), the environmental-interpersonal effects (Money, 1974), and cognitive development (Piaget, 1968; Kohlberg, 1966). However, few studies are reported on the psychosexual development of retarded children. The present study was undertaken to assess a basic milestone in the psychosexual development of retarded children-namely, to examine the relationship between chronological age and mental age in the development of gender identity. Presumably, seeing oneself as a boy or a girl affects the individual's self-concept and normal development of the appropriate sex role.

'Address all correspondence to Dr. Geoffrey Abelson, Department of Elementary Education, 202 Quadrangle-North, Iowa State University, Ames, Iowa 50011. 
Thus the attainment of gender identity may be especially critical in retarded children who frequently have problems in these two areas.

Gender identity refers to the ability of a child to identify himself/herself as a boy or a girl. This is quite different from the concept of "gender constancy," which refers to recognition of the permanency of gender identity and thus to a more advanced step in psychosexual development. Likewise, gender identity is different from gender role (or sex role), which refers to the many attributes, attitudes, mannerisms, and other aspects that are considered masculine or feminine (Mussen, 1969). Certainly, in normal psychosexual development, the formation of gender identity greatly influences the child's subsequent gender role. Yet it is possible to separate these two concepts. For example, a boy may know on a cognitive level that he is a boy, yet his behavior and interests may cause him to be labeled "feminine." Conversely, a boy may act in a prescribed "masculine fashion"; during psychological testing or even on direct questioning, however, he may reveal confusion about his gender identity.

In this study gender role was not assessed, only gender identity. The authors were interested in determining if there exists a significant difference between the age of attainment of gender identity in retarded versus normal children and, furthermore, if there is a correlation between the degree of retardation and the extent of delay in development of gender identity.

In reviewing the literature on gender identity the authors were unable to find a single study done on retarded children. The only study that investigated the role of IQ dealt with average and above-average children's performance on a number of sex role tests. As part of their study with 4- to 8 -year-old children of average and above-average intelligence, Kohlberg and Zeigler (1967) included a comparison of imitation of male and female models, selection of male and female dolls, selection of sex-typed pictures, and performance on the "IT" scale (Brown, 1956). Generally, the aboveaverage children showed earlier trends of sex role development; however, these trends were not consistently statistically significant.

Even studies on the development of gender identity in normal children are relatively sparse. Most of these studies fall into two categories: first, studies aimed at analyzing the cues children use in discriminating between the sexes; and second, studies focusing on the age when the child recognizes himself/herself as a boy or a girl. In discriminating between the sexes young children primarily use cranial hair and clothes as the major cues. In identifying dressed and undressed cutout figures, Katcher (1955) found that 3-year-olds and older children could identify the dressed figures accurately, yet even 6-year-old children made errors on the undressed figures. In a study by Thompson and Bentler (1971), children 4 to 6 years of age used hairstyle and body type, rather than genital differences, as the primary cues to identify sex. 
Gesell, Halverson, Thompson, Ilg, Costner, Ames, and Amatruda (1940) first attempted a systematic way of determining if a child is aware of his/her gender identity by asking the child, "Are you a little boy or a little girl?" Gesell found that most children between 30 and 36 months could answer this question correctly. A similar result was found by Rabban (1950). Using the Michigan Gender Identity Test (MGIT), Paluszny, BeitHallahmi, Catford, Cooley, Dull, and Guiora (1973) found that $25 \%$ of children between 25 and 27 months of age could accurately categorize as male or female photographs of other children as well as their own pictures; by 34 to 37 months, almost all the subjects completed the MGIT without error. Using a similar procedure, Thompson (1975) found that at 24-25 months $82 \%$ of the children could identify their own picture and $76 \%$ of the subjects correctly labeled pictures of boys, girls, men, and women. At 30 months, $100 \%$ of the subjects correctly labeled their own photographs and $83 \%$ of the subjects correctly identified boys, girls, men, and women.

From the foregoing studies, it appears gender identity occurs in most children between 30 and 36 months of age. Furthermore, children use the cues of dress and body type to distinguish between males and females.

\section{METHOD}

\section{Subjects}

To evaluate development of gender identity in retarded children, 52 retarded children were compared with 36 normal children. The retarded children were drawn from special education classes in four different schools. The group consisted of 26 boys and 26 girls ranging from 3 years 1 month to 10 years 6 months, with a mean of 5 years 8 months. The IQ range of the group as measured by the Stanford Binet was 30 to 84, with a mean of 64 . The mental age of the group was 2 years to 6 years 11 months, with a mean of 3 years 8 months.

The verbal ability of the children varied and was congruent with their intelligence levels. Of these children, 12 used only single words, 21 spoke in two- and three-word phrases, and 18 spoke in sentences. One child had no expressive language. Because of the limited verbal ability of the children, it was felt that the MGIT was a particularly useful test, as the children could do all parts of the test without using language at all.

In view of the present trend to measure degree of retardation by both IQ and some adaptive behavior scale, such as the AAMD Behavior Scales, it would be desirable to include such data. However, at the time of this study, systematically collected behavioral information was not available on the sample of retarded children. 
The control group of 36 children was drawn from children attending a co-op nursery, a children's play group, and a day school. There were 19 boys and 17 girls ranging in age from 2 years 1 month to 5 years 6 months, with a mean of 3 years 6 months. All the children were judged by their teachers to be of average or above-average intelligence. However, a Peabody picture vocabulary test was given to all the children to get an approximation of their intelligence level. By using this test it was found that 4 children in the control group rated IQ scores between 85 and 95 . After some debate on the pros and cons of including these 4 children, it was decided to keep them as part of the control group. It was theorized that if the control group was to be truly representative of a normal population, overtly normal behavior and lack of developmental delays had to be the criteria for selection. Furthermore, if IQ became the major criterion for selection of the control group, it would be difficult to compare the results of our study with previous studies where IQ was not ascertained.

In this group verbal ability again paralleled intelligence level; thus the children were generally more verbal. Five of the children used single words, 5 used two- or three-word phrases, and 26 children spoke in sentences.

In order to minimize sociocultural effects, only Caucasian middleclass children from intact families were used for both the experimental and the control groups.

\section{Procedure}

The Michigan Gender Identity Test was used to determine if the child had attained gender identity. This test was developed by the University of Michigan Personality Variables in Language Behavior Research Project. The test was first used to assess gender identity in normal children (Paluszny et al., 1973), and subsequently the test procedure has been reported in detail (Dull, Guiora, Paluszny, Beit-Hallahmi, Catford, \& Cooley, 1975). Basically, the test is a simple identification and sorting task in which children first identify familiar objects (i.e., separate photographs of dogs from pictures of balls), then identify girls and boys, and finally identify their own picture, which has been placed among other photographs of boys and girls. All the photographs of the children are stereotyped pictures of girls in dresses and boys who have short hair and wear long pants.

In order for a child to be judged as having attained gender identity, he/she must complete all parts of the test. The dog/ball segment is intended to familiarize the child with the test and to assess if the child can sort the pictures either by verbally labeling the object or by sorting into groups, or by pointing to the object named by the examiner. Thus expressive verbal 
ability is not necessarily a prerequisite for the test. The next section of sorting pictures of boys and girls is meant to determine if the child can accurately differentiate the two groups. It is argued that without this concept the child cannot really be aware of his own gender identity. This point was illustrated when the MGIT was first used on normal children. One boy correctly said he was a boy; however, when he was identifying the pictures of boys and girls he referred to all the pictures as "boys"!

In addition to the MGIT, all the children were asked the Gesell question, "Are you a little boy or a little girl?"

\section{RESULTS}

In the group of retarded children there was no significant correlation between chronological age and performance on the MGIT (Table I). There was, however, a significant correlation between mental age and performance on the MGIT, $r(50)=.4812, p<.01$ (Table II). Thus it appears that in the group of retarded children, age itself was not an important factor in improving the children's performance on the MGIT. IQ was, however, the critical factor in the development of the concept of gender identity, $r(50)=$ $.4437, p<.01$. In the control group of normal children, where mental age closely paralleled chronological age, the performance on the MGIT showed a significant correlation with both chronological age, $r(34)=.5689$, $p<.01$ (Table III), and mental age, $r(34)=.5014, p<.01$ (Table IV).

When the data obtained by the Gesell question ("Are you a little boy or are you a little girl?') were compared with the results of the MGIT, it was found that children in both groups who successfully completed all MGIT items also correctly answered the Gesell question. Conversely, a few of the children who answered the Gesell question correctly did not answer all the MGIT items correctly. In the control group, three subjects $(8 \%)$

Table I. Correct MGIT Responses by Chronological Age, $N=52$ (Retarded Children) ${ }^{a}$

\begin{tabular}{|c|c|c|c|c|c|}
\hline Age in months & Dogs/balls & Girls/boys & Self & Question & Total in group \\
\hline $37-48$ & 6 & 3 & 3 & 4 & 7 \\
\hline $49-60$ & 18 & 14 & 15 & 14 & 20 \\
\hline $61-72$ & 9 & 7 & 8 & 7 & 9 \\
\hline $73-84$ & 5 & 3 & 3 & 3 & 5 \\
\hline $85-96$ & 4 & 2 & 3 & 2 & 4 \\
\hline $97-126$ & 7 & 7 & 6 & 6 & 7 \\
\hline
\end{tabular}


Table II. Correct MGIT Responses by Mental Age, $N=52$ (Retarded Children) ${ }^{a}$

\begin{tabular}{cccrcc}
\hline Age in months & Dogs/balls & Girls/boys & Self & Question & Total in group \\
\hline 24 & 1 & 0 & 0 & 0 & 2 \\
$25-36$ & 10 & 4 & 5 & 5 & 11 \\
$37-48$ & 27 & 22 & 24 & 21 & 28 \\
$49-60$ & 3 & 2 & 1 & 2 & 3 \\
$61-83$ & 8 & 8 & 8 & 8 & 8 \\
\hline
\end{tabular}

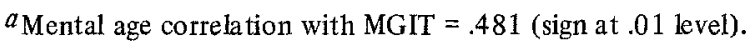

Table III. Correct MGIT Responses by Chronological Age, $N=36$ (Normal Children) ${ }^{a}$

\begin{tabular}{cccccc}
\hline Age in months & Dogs/balls & Boys/girls & Self & Question & Total in group \\
\hline $25-36$ & 14 & 7 & 7 & 7 & 14 \\
$37-48$ & 7 & 7 & 7 & 7 & 7 \\
$49-66$ & 15 & 14 & 14 & 15 & 15 \\
\hline
\end{tabular}

${ }^{a}$ Chronological age correlation with MGIT $=.5689$ (sign at .01 level).

Table IV. Correct MGIT Responses by Mental Age, $N=36$ (Normal Children) $^{a}$

\begin{tabular}{cccccc}
\hline Age in months & Dogs/balls & Boys/girls & Self & Question & Total in group \\
\hline $27-36$ & 11 & 5 & 7 & 5 & 11 \\
$37-48$ & 8 & 6 & 5 & 7 & 8 \\
$49-60$ & 5 & 5 & 4 & 5 & 5 \\
$61-72$ & 6 & 6 & 6 & 6 & 6 \\
$73-100$ & 6 & 6 & 6 & 6 & 6 \\
\hline
\end{tabular}

${ }^{a}$ Mental age correlation with MGIT $=.5014$ (sign at .01 level).

answered correctly if they were a boy or a girl but could not complete the MGIT; while in the retarded group, four subjects (7\%) answered the Gesell question correctly but could not complete the MGIT. Possibly the MGIT, by including the concept of categorizing other children into male and female, is a more demanding test of gender identity; also, children cannot "guess" on the MGIT but can on the Gesell question. Nevertheless, generally both the MGIT and the Gesell question showed similar results.

In comparing males with females on their performance on the MGIT, no significant differences were found in either the retarded group, $t(51)=$ 1.670 , or the control group, $t(35)=-.283$ (Table V). 
Table V. Comparison of Correct MGIT by Sex

\begin{tabular}{lccccc}
\hline & Total & Males & Females & $t$ & $d f$ \\
\hline Normal & 26 & 12 & 14 & $-.283^{a}$ & 35 \\
Retarded & 32 & 18 & 14 & $1.670^{a}$ & 51 \\
\hline$a$ Not significant. & & & &
\end{tabular}

\section{DISCUSSION}

The preceding data indicate that gender identity does not develop as a factor of chronological age. Rather, it is a cognitive process that develops according to mental age. This finding supports Kohlberg's view (1966) that observational learning and maturing cognitive abilities are jointly responsible for early gender labeling or categorization of oneself. As represented by Kohlberg, the cognitive developmental view of gender identity moves sequentially through three levels. First, a child recognizes that he/she and everyone else are male or female. Second, the child understands boys invariably become men and girls become women. Third, the attributes of being male or female are realized to be constant despite changing situations. This last state of stabilization of gender identity parallels the general stabilization of constancies of physical objects that occurs at 6 or 7 years of age. If we accept this view of the development of gender identity and gender constancy, and also consider Rutter's (1971) view that the child's individual feelings in recognizing himself as a boy or girl are important in sex role development, then the delay in formation of gender identity may affect the entire psychosexual development of the retarded child.

It is likely that the retarded child's delay in the formation of gender identity, i.e., a delay in viewing himself/herself as a boy or a girl, is then followed by a delay in successive psychosexual milestones. Thus the retarded child quite possibly will have problems in appropriate sex role development.

Anyone working with retarded individuals is familiar with their problems in learning appropriate sex role behavior. Often, the retarded adolescent or adult may be inappropriately seductive or overly fearful of any behavior even vaguely connected with sexuality. Usually such inappropriateness is ascribed to a lack of understanding of social situations or to problems in understanding abstract concepts or even just to the consequences of a limited IQ. It seems from our study, however, that one of the major problems may be a result of delay in appropriate psychosexual development. If the retarded child is delayed in seeing himself/herself as a boy or a girl, then surely this individual will have difficulties understanding how he/she should act as a male or a female. 
Unfortunately, the area of psychosexual development in the retarded is sadly neglected. Not only is research extremely limited in this area, but even on a practical, commonsense level sexuality in the retarded is ignored. Except for basic hygiene, no attempt is made to teach any aspects of sexuality in most special education classes or in outpatient or inpatient facilities for the retarded. Such children are not helped to recognize themselves as males or females, differences from the opposite sex are not explained, and the word sex is never mentioned.

Since gender identity correlates with mental age and IQ, it is quite reasonable to expect that with time and additional training, retarded children can learn gender identity and eventually more complicated psychosexual concepts such as gender constancy and gender role. The problem seems to be to provide retarded children sufficient opportunities to learn these basic concepts, which normal youngsters learn with no effort.

In summary, it is obvious from a theoretical standpoint that much more research should be done on the psychosexual development of retarded children. From a practical point of view, however, it appears that retarded children may need more help from specialized professionals as well as from parents and teachers to facilitate the development of core gender identity.

\section{REFERENCES}

Brown, D. G. Sex-role preference in young children. Psychological Monographs, 1956, 70(14, Whole No. 429).

Dull, C., Guiora, A. Z., Paluszny, M., Beit-Hallahmi, B., Catford, J. C., \& Cooley, R. The Michigan Gender Identity Test (MGIT). Comprehensive Psychiatry, 1975, 16, 581-592.

Gesell, A., Halverson, H. M., Thompson, H., Ilg,.F. L., Costner, B. M., Ames, L. B., \& Amatruda, C. S. The first five years of life: $A$ guide to the study of the preschool child. New York: Harper, 1940.

Katcher, A. The discrimination of sex differences by young children. Journal of Genetic Psychology, 1955, 87, 131-143.

Kohlberg, L. A cognitive-developmental analysis of children's sex-role concepts and attitudes. In E. Maccoby (Ed.), The development of sex differences. Stanford, California: Stan ford University Press, 1966.

Kohlberg, L., \& Zeigler, E. The impact of cognitive maturity on the development of sex-role attitudes in years four to eight. Genetic Psychology Monographs, 1967, 75, 89-165.

Money, J. Prenatal hormones and postnatal socialization in gender identity differentiation. In J. K. Cole \& M. Dienstbier (Eds.), Nebraska symposium on motivation. Lincoln: University of Nebraska, 1974.

Mussen, P. Early sex-role development. In D. A. Goslin (Ed.), Handbook of socialization theory and research. Chicago: Rand McNally, 1969.

Paluszny, M.,-Beit-Hallahmi, B., Catford, J. C., Cooley, R., Dull, C., \& Guiora, A. Z. Gender identity and its measurement in young children. Comprehensive Psychiatry, $1973,14,281-290$.

Piaget, J. On the development of memory and identity. Barre, Massachusetts: Clark University Press, 1968.

Rabban, M. Sex-role identification in young children in two diverse social groups. Genetic Psychology Monographs, 1950, 42, 81-158. 
Rutter, M. Normal psychosexual development. Journal of Child Psychology and Psychiatry, $1971,11,259-283$.

Stoller, R. J. Sex and gender. London: Hogarth Press, 1968.

Thompson, S. K. Gender labels and early sex role. Child Development, 1975, 46, 339-447.

Thompson, S. K., \& Bentler, P. M. The priority of cues in sex discrimination by children and adults. Developmental Psychology, 1971, 6, 181-185. 